\title{
How Jordanian Youth Perceive Social Networks Influence?
}

\author{
Emad A. Abu-Shanab ${ }^{1, *}$, Heyam A. Al-Tarawneh ${ }^{2}$ \\ ${ }^{1}$ MIS Department, Yarmouk University, 21163, Irbid, Jordan \\ ${ }^{2}$ Ministry of Education, Irbid Directorate, 21163, Irbid, Jordan \\ *Corresponding author: abushanab@yu.edu.jo
}

Copyright $@ 2013$ Horizon Research Publishing All rights reserved.

\begin{abstract}
Social networks (SN) hit the Arab world strongly in the last few months, where young people communicated, collaborated, and shared all sorts of information and files through Facebook and other types of SNs. It is not clear how young people perceive this type of activity and how they are influenced in their daily livings. It is important to understand how young people see Facebook and understand its advantages and disadvantages. This study utilized 206 responses from different categories mainly undergraduate students (paper survey) and Facebook users (electronic survey) and concluded that the highest perceived advantage of SN is "I can search and find new and old friends (classmates \& relatives)" and the highest perceived disadvantage is "Excessive addiction". Conclusions and future work are reported at the end.
\end{abstract}

Keywords Social Networks, Facebook, Jordan, Empirical Test, Advantages, Disadvantages

\section{Introduction}

Till the advent of the Internet, societies were limited by geographic boundaries, where they utilized traditional mail to interact. The Internet revolutionized the way we interact and socialize crossing geographic boundaries and bridging many obstacles between individuals. This revolution opened new ways of communication such as email, online forums, blogs, and social networking websites such as Facebook. These new channels provided social mobility outside the limits of space and time.

Social networking sites in general and Facebook, in particular, are useful and helpful in communicating among relatives, families, and friends no matter where they are located. The recent versions of social networks can be described as: easy and flexible to use approaches in learning, save time, reduce cost, fitness information [1]. Facebook started as a tool for sharing information among college students more easily through a single site that provides many services and has the ability of posting easily all types of data such as messages, images, video clips, and music. Then, it evolved into an online application that enables an average person with relative ease to establish a personal profile and post any kind of information he/she likes. Research indicates the importance of social networks as a commercial application among teenagers and young adults, where parental rules and regulations have no significant influence on child's use of such sites [2]. Even government started to utilize social media for the purpose of reaching their citizens [3]. Finally, Cisco Company utilized social networks through a tool they called "Cisco SocialMiner" to connect activities of their customers to their social network team to respond in real time and be close to customers [4].

Social Networking Watch is a website that tracks the news of social networks and reports latest events and statistics related to such phenomenon. The site reported that Facebook overtook the first place as the most visited website defeating Google and Yahoo mail [5]. Also, statistics indicate that users spent more time on Facebook than the other two websites (user engagement). Students form the highest percentage of SNSs users; also they form $37 \%$ of the total population [6]. In the Middle East, as reported by the same site, different utilization is witnessed as Jordanians are bringing attention to environmental issues, Egyptians are exchanging news related to police brutality, and Lebanese are using social network to promote a culture of peace.

We can conclude that as much as social networks (SNs) have their social benefits they also have their drawbacks. Facebook is the most blocked website by network firewalls of businesses [7], because employees are spending too much time on these websites. Also, social networks are efficient tools for terrorism, as the Internet provided an environment to post, promote and exchange news and messages related to anti-peace directions. SNs disseminate huge amount of information at the expense of quality. Young individuals are vulnerable to this information since they cannot validate the reliability of such information. In addition, Facebook links people to other websites that exploits people's information and fails to provide protection from these websites. Moreover, Facebook, for some users, is a time killing machine taking their attention away from browsing useful 
knowledge from other channels in the Internet. In the Arab region, in particular, Facebook is used by Arab users to disseminate personal photos, video clips, jokes.... etc, which has very little value of knowledge to users.

The use of social networking by young people and its impact on their behavior pose many questions such as: What are the threats that surround the social behavior of these young people? What are the rights and obligations of the social networking sites to ensure the quality and protection for their users? Which websites target youth activities for accents stalking and embezzlement? This work tries to explore how young people perceive the influence of $\mathrm{SN}$ on the Jordanian society utilizing an empirical research within a university environment.

\section{Literature Review}

Social networks are "part of social media which are applied to any kind of products and services and user generated content which includes conversation, articles, images or pictures, recipes, and anything that an individual share with others in their daily lives" [8, p. 476].

Research indicated that the major motives for using SN are: seeking friends, social support, entertainment, information, and convenience [9]. The study focused on the motivation for using social network sites comparing the cultural differences between American and Korean college students in both countries. They concluded that American users focus on entertainment while in Korea users focus on social support. Morgan, Snelson and Elison-Bowers studied the use of social media websites like YouTube, Facebook, and MySpace by young adults to post images or videos of substance use [10]. In particular, they studied posting images and videos of alcohol and marijuana consumption. The study showed that students positively perceived alcohol postings while negatively viewed postings related to marijuana consumption.

Other research discussed the benefits and the risks of adapting some free online and Internet tools for the use of libraries and librarians in developing countries to better serve their patrons [11]. According to their study, these free online and Internet tools can be combined with library instructions to be used in information literacy training. Among the free online and Internet tools that can be adapted by librarians, the authors focused on social media and Web 2.0 technologies which included the following social networks websites: Facebook, Twitter, blogs, RSS, wikis and video sharing. Since the patrons of many libraries are no strangers for these free online and Internet tools, this will help the librarians understand the library users and help these users become savvier consumers and creators of information. In addition, this will help facilitate the professional development of the librarians especially in geographically isolated developing countries. The authors acknowledge the risks of adapting these technologies by libraries such as unsuccessful implementations where users do not find these library tools and opening to more feedback from library patrons. However, the authors concluded that the benefits outweigh the risks and concerns.

Amichai-Hamburger and Vinitzky studied the connection between the personality of an Internet user and the way he/she behaves online, specifically on Facebook [12]. They explored five well known personality dimensions: neuroticism, extroversion, openness, agreeableness and conscientiousness, where they related many factors like number of friends, number of photos, gender, college, self picture, birthday, group and album. A strong connection was found between the user individual personality and his behavior online. This contradicts with the results of a study that found a weak connection between personality and online behavior of Internet users [13]. The study found that the motivation to communicate was more influential in the case of Facebook.

Shin studied security, privacy, and trust of online social network services (SNS) such as MySpace, Facebook, and Twitter where people share interests and activities online using reliable secured network application [14]. The author emphasized the importance of the three factors: trust, privacy and security, where a two relationship was assumed. Also, explained the differences among security issues, privacy issues, and malicious applications under the environment of social networks. The study concluded that the intention to use social networks applications will result from a composite influence from the three factors, using a survey of SNS users to validate and explain the acceptance of SNS. The survey results showed the importance of security and privacy as antecedents of trust among the users of the SNS.

On the same line, A study explored security, privacy, trust and risk taking of social networks users such as Facebook and My Space [15]. They utilized 205 college students to conclude that students with profiles on social networks sites are at greater risk in terms of privacy than those who do not, and similarly males had greater risk propensity than females. For example, more men display their phone numbers and home addresses than women. Finally, the study showed that Facebook has a greater sense of trust among its users than MySpace. In the same area and exploring the issue of personal information disclosure like: gender, age and other personal information exposed by Facebook users, a three phases study showed that approximately $25 \%$ of all possible personal information that can potentially be revealed by the Facebook users was disclosed. The phases included a scoring tool that was developed to search thoroughly the content of personal profiles; groups were categorized to classify information related to identity, personal and group threats; and a grouping strategy was developed to organize all the information in the Facebook profiles in a meaningful way as a function of the posted content. The study revealed that as age increases, the amount of personal information in profiles decreases. Those seeking a relationship using the social networking sites disclosed the greatest amount of highly sensitive information [16].

Another study examined how much, why, and how an 
adult person uses social network sites. They studied the daily Internet routine of 92 college students to assess their use of the popular social networking sites [17]. Results showed that students used Facebook approximately for an average of 30 minutes throughout the day and was most often used for social interaction with friends and with pre-established relationships offline. Data collected from two sources: a diary-like conducted daily and a post experiment survey conducted after one week of the experiment. The students' profile in Facebook showed information about religion; political ideology and work. In addition to that, users of social networks used media to express their identity and its development during emerging adulthood.

In a longitudinal study that accessed Facebook records twice, all activities of a group of university students were explored through Facebook website. The study took permission from Facebook to access profiles in 2006 and to continue until graduation in 2009 [18]. Researchers concluded that users with similar personal data like gender and racelethnicity would share socioeconomic status indicated by distinct network behaviors, and cultural preferences sharing common social relationship. These findings showed the great potential of the new social networking sites for research purposes. Other research that explored trust in the process of online information disclosure revealed an important role of information relevance, where it directly influences the risk beliefs and attitudes towards disclosing information [19]. Similarly, Viejo and Castellà-Roca studied the threat of profiling users through their search history using Google and Yahoo search engines. They proposed and implemented a protocol to distort the profile of users on a social network domain, where delay in network response was acceptable and offered privacy to users especially with scenarios that did not follow the protocol. Their tests showed an effective way to prevent search engines from profiling users at an affordable price [20].

The latest research on the use of social media (SM) in the educational sector showed that SM can be used for communication, interaction or sharing news, pictures, and videos, and also to connect distant learners to communicate, discuss and arrange meetings [21]. Also, students enjoy Facebook discussions more than online discussions provided by university-sponsored online tool, because they find Facebook familiar, easy to navigate and with attractive interface [22].

Kang and Lee explored user satisfaction in the context of social networks services and concluded that perceived usefulness and enjoyment are important antecedents of users' satisfaction. Also, anxiety had a moderating role on the relationship between website satisfaction and behavioral attitudes. Their conclusions support the influence of both system satisfaction and information satisfaction on usefulness and enjoyment. Also, results showed how preceding experience plays a key role in e-satisfaction and stresses the importance of understanding the role of online services on e-satisfaction [23].
Correa, Hinsley and Zuniga studied three of the big five personality traits: extraversion, emotional stability and openness to experience to the use of social applications on the Internet. The study concluded that extraversion and openness to experience positively related to use of social networks, while emotional stability negatively related to usage [24]. Gender and age were significant moderators of such relationships. The study examined social media use including the use of social networking sites and instant messages.

Table 1. Means of the survey items

\begin{tabular}{|c|c|c|c|}
\hline$\#$ & Item & Mean & $\begin{array}{l}\text { Std. } \\
\text { Dev. }\end{array}$ \\
\hline 1 & $\begin{array}{l}\text { I can search and find new and old friends } \\
\text { (classmates \& relatives) }\end{array}$ & 4.43 & 0.90 \\
\hline 2 & $\begin{array}{l}\text { I can find new opportunities for work, travel } \\
\text { and education }\end{array}$ & 3.45 & 1.09 \\
\hline 3 & $\begin{array}{l}\text { It makes it less difficult when } \\
\text { communicating with strangers for the first } \\
\text { time }\end{array}$ & 3.88 & 1.11 \\
\hline 4 & $\begin{array}{l}\text { It makes it easy for me to join groups with } \\
\text { similar interests (likes and dislikes) }\end{array}$ & 4.05 & 1.06 \\
\hline 5 & $\begin{array}{l}\text { I can find required information easily } \\
\text { through network contacts }\end{array}$ & 4.01 & 0.96 \\
\hline 6 & $\begin{array}{l}\text { I can find accommodations and locations } \\
\text { easily }\end{array}$ & 3.62 & 1.07 \\
\hline 7 & $\begin{array}{l}\text { I can target specific people for } \\
\text { marketing/relationship and for free }\end{array}$ & 3.64 & 0.97 \\
\hline 8 & $\begin{array}{l}\text { I can network with other professionals in } \\
\text { my field }\end{array}$ & 4.17 & 1.00 \\
\hline 9 & It is entertaining and amusing & 4.38 & 0.91 \\
\hline 10 & $\begin{array}{l}\text { I can get immediate feedback on ideas and } \\
\text { requests }\end{array}$ & 3.86 & 0.95 \\
\hline 11 & $\begin{array}{l}\text { More and more people (overwhelming - } \\
\text { overcrowding) }\end{array}$ & 3.32 & 1.26 \\
\hline 12 & Long distance relationship weakening & 3.04 & 1.28 \\
\hline 13 & Unsupported by physical adjacency & 3.60 & 1.04 \\
\hline 14 & $\begin{array}{l}\text { Exposing more information about me } \\
\text { (privacy risk) }\end{array}$ & 3.61 & 1.26 \\
\hline 15 & Excessive addiction & 4.10 & 1.13 \\
\hline 16 & Possible stalking from unwanted people & 3.89 & 1.20 \\
\hline 17 & Acquaintances being labeled as friends & 3.50 & 1.25 \\
\hline 18 & Takes a long time to build real relationships & 3.65 & 1.18 \\
\hline 19 & $\begin{array}{l}\text { Loss of face-to-face contact } \\
\text { (communication) }\end{array}$ & 3.90 & 1.13 \\
\hline 20 & Waste of time and resources & 3.56 & 1.33 \\
\hline
\end{tabular}

\section{Facebook Pros and Cons}

Facebook has no clear advertising policy, thus many researchers doubt the agenda behind establishing such network [25]. The same source claims that the privacy policy of Facebook grants the right to oversee users' information and use it for statistical and commercial purposes. Also, the site cannot protect against publishing any personal data of users and against identity theft (same source). In the previous section, we explored the literature related to $\mathrm{SN}$ and pointed some of its pros and cons. It is important to realize the advantages and disadvantages of Facebook, knowing that it will influence all aspects of our lives. In the business arena, 
advertising using Facebook was reported with many advantages like: customer reach, increased targeting and more efficient local targeting, and offers a variety of tools (exposure and awareness vs. conversion and richness of information). The same source list some cons of Facebook advertising like: lower conversion rate to e-commerce, irrelevant ads, and high cost for some niche areas [26].

On the personal side, comprehensive studies that empirically explore the pros and cons of SN users are limited. Up to the knowledge of the researcher, no studies investigated the perceptions of young people towards the pros and cons of SN. Based on the previous literature, a list of 10 pros and 10 cons of SN was constructed and as listed in Table 1, which comprises the major survey items used in this exploratory research [9] [13] [14] [15] [17] [19] [23] [25] [26] [27] [28] [29].

\section{Research Method}

This study tried to explore how young people in Jordan perceive social networks advantages and disadvantages. The major research questions introduced are:

RQ1: How young Jordanians see the influence of social networks?

RQ2: Is there any influence generated by gender?

RQ3: Would results differ based on data collection method?

The study utilized two data collection channels: a paper survey distributed on undergraduate students and a link sent to an e-mail list and a Facebook group to fill the same survey online. The survey was adapted to the Jordanian environment and translated to Arabic language to make it easier for subjects to better understand the items as all subjects were Arabs. The survey utilized a 5 point Likert scale, with (5) representing "totally agree" and (1) representing "totally disagree". Based on that, a value more than 3.5 would be considered "high"; a value between 2.5-3.5 would be considered moderate; and finally a value below 2.5 would be considered low. The paper version was distributed on two first year sessions in an undergraduate class at a public university. The electronic version was distributed through an e-mail list and 2 Facebook groups (total 400 addresses). The sample totaled 206 subjects with 107 (52\%) filling the paper survey and 99 (48\%) filling it online (response rate of electronic version $=25 \%$ ). The survey included 20 questions summing the major advantages and disadvantages of social networks (Refer to Table 1). Males accounted for $46 \%$ of the sample (95 subjects) and females 54\% (111 subjects). Finally, 171 subjects (83\%) indicated that they have a Facebook account while 67 subjects $(33 \%)$ indicated that they have another type of social network account like MySpace, Hi 5, Twitter, or LinkedIn. This does not mean that respondents with another SN account did not have a Facebook account as 139 indicated that they don't have other than Facebook account.

To answer research question 1 , descriptive analysis was conducted estimating the means for each response. Table 1 lists the items used in the survey and the means and standard deviation for each. Data indicates the importance of all items listed in the survey as all means were higher than 3. Such value is considered moderate in social sciences (3.5-5 is considered high). Only items 2, 11 and 12 were less than 3.5 (moderate), where the highest items that respondents agreed on were $1($ mean $=4.43), 9($ mean $=4.38)$ and $8($ mean $=4.17)$ on the positive side of SNs, and $15($ mean $=4.10), 19$ (mean $=3.90)$ and $16($ mean $=3.89)$ on the negative side of SN. Finally, the lowest perceived advantage of Facebook was finding new opportunities for travel and education (mean = 3.45 ), and the lowest perceived disadvantage was weakening long distance relationships ( mean $=3.04$ ).

Table 1 also shows that Young Jordanians perceived Facebook as a positive phenomenon as the calculated mean of all items from 1-10 $($ mean $=3.95)$ was higher than the mean of all items from 11-20 $($ mean $=3.62)$. On the other hand, it seems that Jordanians had more disputes regarding pros and cons related to SNs as the mean of standard deviations of the first ten items (the mean of the first 10 standard deviations $=1.00$ ) was smaller than the mean of standard deviations of the last ten items (the mean of the last 10 standard deviations $=1.21$ ) .

To answer research questions 2 and 3 , two sets of ANOVA tests were conducted on the data with gender and data collection method (paper vs. electronic) as determinant factors respectively. Results are demonstrated in Tables 2 and 3. Data indicated no significant influence at $(\alpha<0.05)$ based on gender between the means of all items in the survey except for item number 19 (Loss of face-to-face contact (communication)). On the other hand, data indicated significant differences in 3 items: 4 (It makes it easy for me to join groups with similar interests (likes and dislikes), at ( $\alpha$ $<0.001)$ ), 6 (I can find accommodations and locations easily, at $(\alpha<0.05))$ and 15 (Excessive addiction, at $(\alpha<0.05)$ ).

Table 2. ANOVA comparisons based on gender

\begin{tabular}{|c|c|c|}
\hline Item & F value & Sig. \\
\hline Q1 & 1.711 & 0.192 \\
\hline Q2 & 1.469 & 0.227 \\
\hline Q3 & 1.446 & 0.231 \\
\hline Q4 & 0 & 0.992 \\
\hline Q5 & 3.107 & 0.079 \\
\hline Q6 & 0.005 & 0.941 \\
\hline Q7 & 0.897 & 0.345 \\
\hline Q8 & 0.548 & 0.46 \\
\hline Q9 & 0.207 & 0.65 \\
\hline Q10 & 2.201 & 0.139 \\
\hline Q11 & 0.677 & 0.412 \\
\hline Q12 & 0.163 & 0.687 \\
\hline Q13 & 0.053 & 0.817 \\
\hline Q14 & 0.137 & 0.712 \\
\hline Q15 & 0.157 & 0.692 \\
\hline Q16 & 0.133 & 0.715 \\
\hline Q17 & 0.7 & 0.404 \\
\hline Q18 & 0.001 & 0.981 \\
\hline Q19 & $\mathbf{4 . 1 4 9}$ & $\mathbf{0 . 0 4 3}$ \\
\hline Q20 & 1.224 & 0.27 \\
\hline
\end{tabular}


Table 3. ANOVA comparisons based on data collection method

\begin{tabular}{|c|c|c|}
\hline Item & F value & Sig. \\
\hline Q1 & 0.04 & 0.842 \\
\hline Q2 & 0.375 & 0.541 \\
\hline Q3 & 0.397 & 0.53 \\
\hline Q4 & 14.14 & $\mathbf{0 . 0 0 0 * * *}$ \\
\hline Q5 & 3.613 & 0.059 \\
\hline Q6 & $\mathbf{5 . 5 5 7}$ & $\mathbf{0 . 0 1 9 *}$ \\
\hline Q7 & 0.19 & 0.663 \\
\hline Q8 & 0.053 & 0.818 \\
\hline Q9 & 1.69 & 0.195 \\
\hline Q10 & 0.129 & 0.72 \\
\hline Q11 & 2.164 & 0.143 \\
\hline Q12 & 1.408 & 0.237 \\
\hline Q13 & 3.018 & 0.084 \\
\hline Q14 & 1.498 & 0.222 \\
\hline Q15 & 4.232 & $0.041 *$ \\
\hline Q16 & 0.004 & 0.947 \\
\hline Q17 & 0.523 & 0.471 \\
\hline Q18 & 2.513 & 0.114 \\
\hline Q19 & 0.233 & 0.63 \\
\hline Q20 & 0.006 & 0.938 \\
\hline & & \\
\hline
\end{tabular}

Considering the utility of research and the values of significance, it is not significant to conduct a correlation analysis between variables as the ANOVA tests were majorly not significant. Also, considering the high significance of items 19 (based on gender), 6 \& 15 (based on collection method), only Q4 can carry a significant influence.

\section{Conclusions and Future Work}

This study tried to explore empirically the advantages and disadvantages of SNs perceived by young Jordanians. All items proposed by the literature were significantly perceived as highly important (only three items were perceived moderately as important). The study focused on Facebook as one type of SN. Such result implies the high level of awareness by Jordanians regarding the pros and cons of SNs. The highest perceived advantage was finding old and new friends (Mean 4.43), while the highest perceived disadvantage was the excessive addiction associated with using Facebook. Also, this study can conclude that gender and collection method have no significant influence on the perceptions of Jordanians.

This exploratory study aimed at finding a set of pros and cons associated with using SNs, and thus more work is needed in many areas to confirm such results. More pros and cons were added after the review process which are not included in the empirical test, but can be considered in future research. Also, the translation of the items (description of pros and cons) need a larger sample to test for the reliability of this instrument. Research is needed to explore other types of networks like LinkedIn, Twitter, and MySpace, where each has its own features. This paper added to the body of knowledge how Jordanians specifically perceive SNs (Facebook), but still with the changes and developments of SNs and the advent of new applications (Like WhatsApp or Instagram), more research in needed to understand this domain much better.

\section{REFERENCES}

[1] Zaidieh, A. (2012). The Use of Social Networking in Education: Challenges and Opportunities. World of Computer Science and Information Technology Journal. Vol. 2(1), pp.18-21, 2012.

[2] Gbadeyan, R. (2010). Direct Marketing to Online Social Network (OSN) Users in Nigeria. International Journal of Marketing Studies, 2(2), November 2010, pp. 275-282.

[3] Khasawneh, R. \& Abu-Shanab, E. (2013). E-Government and Social Media Sites: The Role and Impact. Accepted and expected to appear in the World Journal of Computer Application and Technology Vol. 1(1) July 2013.

[4] Cisco.com, (2011). A report on Cisco Social Minor accessed in January 2011 from: http://www.cisco.com/en/US/products /ps11349/index.html

[5] Socialnetworking.com (2010). More than one report, Accessed from the Internet in 2011 from: http://www.socialnetworkingwatch.com

[6] Ahmed, I., \& Qazi, T. (2011). A look out for academic impacts of Social networking sites (SNSs): A student based perspective. African Journal of Business Management, Vol. 5(12), pp. 5022-5031.

[7] OpenDNS.com (2010). OpenDNS® 2010 Report Web Content Filtering and Phishing. A report accessed in January 2011 from www.opendns.com .

[8] Siricharoen, W. (2012). Social Media, How does it Work for Business? International Journal of Innovation, Management and Technology. Vol. 3(4), pp.476-479.

[9] Kim, Y. Sohn, D. \& Choi, S. (2010). Cultural difference in motivations for using social network sites: A comparative study of American and Korean college students. Computers in Human Behavior, 27 (2011), pp. 365-372.

[10] Morgan, E. Snelson, C. \& Elison-Bowers, B. (2010). Image and video disclosure of substance use on social media websites. Computers in Human Behavior, 26 (2010), pp. 1405-1411.

[11] Click, A. \& Petit, J. (2010). Social networking and Web 2.0 in information literacy. The international Information \& Library Review, (2010) 42, pp. 137-142.

[12] Amichai-Hamburger, Y. \& Vinitzky, G. (2010). Social network use and personality. Computers in Human Behavior, 26 (2010) pp. 1289-1295.

[13] Ross, C., Orr, E. S., Sisic, M., Arseneault, J. M., Simmering, M. J., \& Orr, R. R. (2009). Personality and motivations associate d with Facebook use. Computers in Human Behavior, 25, 578-586. 
[14] Shin, D. (2010). The effects of trust, security and privacy in social networking: A security-based approach to understand the pattern of adoption. Interacting with Computers, 22 (2010), pp. 428-438.

[15] Fogel, J. \& Nehmad, E. (2008). Internet social network communities: Risk taking, trust, and privacy concerns. Computers in Human Behavior, 25 (2009), pp. 153-160.

[16] Nosko, A. Wood, E. \& Molema, S. (2009). All about me: Disclosure in online social networking profiles: The case of FACEBOOK. Computers in Human Behavior, 26 (2010), pp. 406-418).

[17] Pempek, T. Yermolayeva, Y. \& Calvert, S. (2008). College students' social networking experiences on Facebook. Journal of Applied Developmental Psychology, 30 (2009), pp. 227-238.

[18] Lewis, K. Kaufman, J. Gonzalez. M. Wimmer, A. \& Christakis, N. (2008). Tastes, ties, and time: A new social network dataset using Facebook.com. Social Networks, 30 (2008), pp. 330-342.

[19] Zimmer, J. Arsal, R. Al-Marzouq, M. \& Grover, V. (2009). Investigating online information disclosure: Effects of information relevance, trust and risk. Information \& Management, 47 (2010), pp. 115-123.

[20] Viejo, A. \& Castellà-Roca, J. (2010). Using social networks to distort users' profiles generated by web search engines. Computer Networks, 54 (2010), pp. 1343-1357.

[21] Hamat, A., Embi, M., \& Hassan, H. (2012). The Use of Social Networking Sites among Malaysian University Students. International Education Studies, Vol.5 (3), pp.56-66.

[22] Hurt, N., Moss, G., Bradley, C., Larson, L., Lovelace, M.,
Prevost, L., Riley, N., Domizi, D., \& Camus, M. (2012). The 'Facebook' Effect: College Students' Perceptions of Online Discussions in the Age of Social Networking. International Journal for the Scholarship of Teaching and Learning, Vol.6(2), pp. 1-24.

[23] Kang, Y. \& Lee, H. (2009). Understanding the role of an IT artifact in online service continuance: An extended perspective of user satisfaction. Computers in Human Behavior, 26 (2010), pp. 353-364.

[24] Correa, T., Hinsley, A. \& Zuniga, H. (2009). Who interacts on the Web? The intersection of users' personality and social media use. Computers in Human Behavior, 26 (2010), pp. 247-253.

[25] Al-Dtheeb, M. (2010). Facebook: an invention that has its harms. Accessed from the Internet in 2011 from: www.aljazeera.net.

[26] Grinaker, A. (2010). Advantages and Disadvantages of Facebook Advertising. Accessed in April 2011 from: http://www.andrewgrinaker.com/2010/03/03/advantages-and -disadvantages-of-facebook-advertising/\#comments.

[27] Findlay, L. (2011). Facebook Advantages and Disadvantages. Accessed in January 2011 from: http://ezinearticles.com/?Fa cebook-Advantage-and-Disadvantages \&id=2051514.

[28] Jain, N., Verma, A., Verma, R., \& Tiwari, P. (2012). Going Social: The Impact of Social Networking in Promoting Education. IJCSI International Journal of Computer Science, Vol. 9 (1), pp. 483-485.

[29] Tariq, W., Mehboob, M., Khan, M., \& Ullah, F. (2012). The Impact of Social Media and Social Networks on Education and Students of Pakistan. IJCSI International Journal of Computer Science Issues, Vol.9 (3), pp.407-412. 